\title{
Combination of Fluorescent Reporters for Simultaneous Monitoring of Root Colonization and Antifungal Gene Expression by a Biocontrol Pseudomonad on Cereals with Flow Cytometry
}

\author{
Laurène Rochat, ${ }^{1}$ Maria Péchy-Tarr, ${ }^{1}$ Eric Baehler, ${ }^{1}$ Monika Maurhofer, ${ }^{2}$ and Christoph Keel ${ }^{1}$ \\ ${ }^{1}$ Department of Fundamental Microbiology, University of Lausanne, $\mathrm{CH}-1015$ Lausanne, Switzerland; ${ }^{2}$ Plant Pathology, \\ Institute of Integrative Biology, Swiss Federal Institute of Technology (ETH), CH-8092 Zürich, Switzerland
}

Submitted 18 January 2010. Accepted 6 March 2010.

\begin{abstract}
Some root-associated pseudomonads sustain plant growth by suppressing root diseases caused by pathogenic fungi. We investigated to which extent select cereal cultivars influence expression of relevant biocontrol traits (i.e., root colonization efficacy and antifungal activity) in Pseudomonas fluorescens CHA0. In this representative plant-beneficial bacterium, the antifungal metabolites 2,4-diacetylphloroglucinol (DAPG), pyrrolnitrin (PRN), pyoluteorin (PLT), and hydrogen cyanide $(\mathrm{HCN})$ are required for biocontrol. To monitor host plant effects on the expression of biosynthetic genes for these compounds on roots, we developed fluorescent dual-color reporters suited for flow cytometric analysis using fluorescence-activated cell sorting (FACS). In the dual-label strains, the constitutively expressed red fluorescent protein mCherry served as a cell tag and marker for root colonization, whereas reporter fusions based on the green fluorescent protein allowed simultaneous recording of antifungal gene expression within the same cell. FACS analysis revealed that expression of DAPG and PRN biosynthetic genes was promoted in a cereal rhizosphere, whereas expression of PLT and HCN biosynthetic genes was markedly less sustained. When analyzing the response of the bacterial reporters on roots of a selection of wheat, spelt, and triticale cultivars, we were able to detect subtle species- and cultivar-dependent differences in colonization and DAPG and HCN gene expression levels. The expression of these biocontrol traits was particularly favored on roots of one spelt cultivar, suggesting that a careful choice of pseudomonad-cereal combinations might be beneficial to biocontrol. Our approach may be useful for selective single-cell level analysis of plant effects in other bacteria-root interactions.
\end{abstract}

Some strains of root-colonizing fluorescent pseudomonads are known for their capacity to keep in check root-pathogenic

Corresponding authors: Christoph Keel; Telephone (+41) 21-692-5636; Fax (+41) 21-692-5605; E-mail: christoph.keel@unil.ch; and Monika Maurhofer; Telephone (+41) 44-632-3868; Fax (+41) 44-632-1572; Email: monika.maurhofer@agrl.ethz.ch

Current address of E. Baehler: Federal Department of Home Affairs, Federal Office of Public Health, Section Biological Safety, CH-3011 Bern, Switzerland. fungi and oomycetes that can cause considerable damage to crop health and yield (Haas and Défago 2005; Lugtenberg and Kamilova 2009; Raaijmakers et al. 2009). These plant-beneficial bacteria produce a diversity of metabolites with broadspectrum antimicrobial activity, of which 2,4-diacetylphloroglucinol (DAPG), pyoluteorin (PLT), pyrrolnitrin (PRN), phenazines, hydrogen cyanide $(\mathrm{HCN})$, and cyclic lipopeptides have been studied in detail because of their important function in biocontrol of root diseases (Gross and Loper 2009; Haas and Keel 2003; Raaijmakers et al. 2006). DAPG and phenazines contribute to the natural suppressiveness of certain soils to soilborne pathogens (Mazurier et al. 2009; Weller et al. 2007). Most biocontrol pseudomonads produce at least one whereas some strains, such as Pseudomonas fluorescens $\mathrm{CHA} 0$ used in this study (discussed below), produce almost the entire repertoire of the abovementioned antimicrobial compounds. The toxic metabolites are known for their activity against fungal plant pathogens but they also may exhibit antibacterial, antiprotozoan, antinematode, and phytotoxic activities (Dubuis et al. 2007; Gross and Loper 2009; Haas and Keel 2003; Jousset et al. 2009; Raaijmakers et al. 2006). Some of them exert remarkably diverse additional functions as signals affecting gene expression in the producer bacterium, mediating cross-communication with other rhizobacteria, and stimulating plant responses (Lugtenberg and Kamilova 2009; Maurhofer et al. 2004; Schnider-Keel et al. 2000). Because of their crucial function in biocontrol and ecological interactions in the rhizosphere, the detailed study of environmental factors that impact expression of these antimicrobial factors in Pseudomonas spp. is of prime importance.

The growth, activity, and diversity of root-associated bacteria may vary in response to the biotic and abiotic rhizosphere environment of a particular plant host (Berg and Smalla 2009). Plant effects on rhizobacteria are likely to be mediated by compounds (signals and nutrients) released by roots that may vary in abundance and diversity depending on constitutive and temporally varying characteristics of a particular host (Bais et al. 2006; Lugtenberg and Kamilova 2009). Up to now, reports on plant host-specific influences on pseudomonads have been largely restricted to the observation of effects on the abundance and diversity of specific functional groups (Berg and Smalla 2009). Prominent examples are the specific populations of DAPG-producing pseudomonads that are enriched in natural disease-suppressive soils intensely cropped with wheat (Weller 
et al. 2007). The enrichment of specific genotypes of DAPG producers is driven by the crop plant at the species and cultivar level (Bergsma-Vlami et al. 2005; Mazzola et al. 2004), suggesting that the plant genotype may specifically shape the pseudomonad community associated with its roots. However, there is still relatively limited data available on the extent to which the plant host influences the expression of beneficial functions in rhizosphere pseudomonads.

An elegant approach to follow the behavior and activity of bacteria on plant surfaces is the use of reporter constructs that are based on autofluorescent proteins, in particular variants of the Aequorea green fluorescent protein (GFP) and the Discosoma red fluorescent protein (DsRed) (Bloemberg 2007; Larrainzar et al. 2005; Shaner et al. 2004). In plant-associated bacteria, GFP and its color variants and, more recently, DsRed have been widely used as cell tags for studying the behavior of bacterial cells associated with seed, root, and leaf surfaces (Bloemberg 2007; Larrainzar et al. 2005). There is also a growing list of reports on the use of GFP-based constructs to monitor gene expression on plant surfaces (Brandl et al. 2001; Bringhurst et al. 2001; de Werra et al. 2008; Steidle et al. 2001). Up to now, in situ detection and quantification of fluorescence from GFP-expressing reporter cells were mainly done by fluorescence microscopy in combination with digital image analysis. However, this approach is laborious and accurate reporter quantification is often hampered by the highly heterogeneous expression and distribution patterns occurring in bacterial populations colonizing natural environments. Fluorescence-activated cell sorting (FACS)-based flow cytometry is a powerful alternative to overcome some of these limitations, because it allows an extensive assessment of population heterogeneity at the single-cell level, by measuring the optical properties of tens of thousands of individual cells within a short period of time. Thus far, studies involving environmental bacteria have used flow cytometry mainly for enumeration of GFP-tagged bacterial cells and determination of their physiological state (Czechowska et al. 2008).

In our recent work, we have demonstrated that FACS-based flow cytometry is a powerful tool for in situ studies of the activity of beneficial bacteria during interaction with their plant host. We successfully quantified variations in the expression of GFP-based reporter fusions to biosynthetic genes for antifungal compounds by the biocontrol agent $P$. fluorescens $\mathrm{CHA} 0$ on root surfaces, in response to fungal attack of the plant host (de Werra et al. 2008). Strain CHA0 is a representative plant growth-promoting rhizobacterium that produces multiple antifungal compounds (i.e., DAPG, PRN, PLT, and HCN) contributing to its biocontrol activity against root diseases (Baehler et al. 2006; de Werra et al. 2009; Haas and Keel 2003; Keel et al. 1996). In the present study, we have further developed the FACS-based approach by combining it with mCherry, a monomeric DsRed derivative with superior photostability and rapid maturing time (Shaner et al. 2004), and GFP coexpressing dual-reporter strains. In the dual reporters, constitutively expressed mCherry serves as a tag for cell identification and quantification of root colonization levels. The GFP-based reporter allows simultaneous monitoring of antifungal gene expression within the same Pseudomonas cell. We show that, with the new approach, population heterogeneity is taken into account more accurately, because even inoculant subpopulations can be identified that do not express a particular antifungal gene in a given rhizosphere condition. We demonstrate that our multiparametric FACS approach is sensitive enough to detect subtle plant genotype-dependent variations in bacterial colonization levels and antifungal gene expression on roots of a selection of wheat, spelt, and triticale cultivars and, thus, may contribute to identify pseudomonad-cereal combinations that optimally sustain plant health.

\section{RESULTS}

P. fluorescens dual-reporter strains for simultaneous monitoring of antifungal gene expression and root colonization by fluorescence-based flow cytometry.

We have developed an experimental approach which allowed us to monitor simultaneously colonization levels and in situ expression of antifungal genes by the biocontrol agent $P$. fluorescens $\mathrm{CHA} 0$ on the roots of different cereal cultivars using a combination of autofluorescent reporter constructs and FACSbased flow cytometry. For this purpose, we tagged $P$. fluorescens $\mathrm{CHA} 0$ by inserting a single copy of the mcherry gene under the control of the constitutive $\mathrm{P}_{t a c}$ promoter at a neutral location into the chromosome using a mini-Tn7-based delivery system. The resulting strain, CHA0-mche, was then transformed with the plasmids pME7100, pME7116, pME7144, or pME7156 containing GFP-based reporter fusions to the DAPG (phlA-gfp), PRN (prnA-gfp), PLT (pltA-gfp), or HCN (hcnA$g f p$ ) biosynthetic genes, respectively (Table 1).

A series of calibration assays were carried out in which the dual reporter CHA0-mche/pME7100 and control strains carrying only one or none of the reporters were grown on roots of the wheat cv. Arina. These assays served to calibrate the settings for the flow cytometric analysis of the root washes, in particular with respect to defining the gates for red and green fluorescence and to determining the detection limits for the reporter constructs. An example of the FACS analysis is shown in Figure 1. As a primary step, a zone R1 encompassing particles of the size and granularity of bacterial cells was defined on the forward scatter (FSC-H)/side scatter (SSC-H) density plots (Fig. 1A through D, right panels). The R1-gated particles include not only the bacterial inoculants but also root particles, bacterial cell fragments, and, because the plant growth pouches were exposed to ambient air, external microbial contaminants. Therefore, the following step consisted of identifying the mCherry-tagged bacterial inoculants among the other particles detected by the flow cytometer. To this end, a gate M2 was set on the FL3-H channel, allowing for subtraction of the red background fluorescence noise produced by the noninoculant particles. The M2 marker was defined on the basis of the red autofluorescence emitted by particles in root washes from wheat plantlets inoculated with strain CHA0/pME7100, which is void of the mCherry tag (Fig. 1A, left panel). A similar red background fluorescence could be observed in samples from plants grown with wild-type $\mathrm{CHAO}$ or without added bacteria (data not shown). Thus, M2-gated events were considered to reflect Pseudomonas inoculants expressing the mCherry tag. Similarly, a gate M1 was set on the FL1-H channel to exclude green background fluorescence when analyzing expression of the GFP-based reporter constructs. The M1 marker was defined based on green autofluorescence detected in root washes from plants inoculated with CHA0-mche (Fig. 1B, middle panel) or wild-type CHA0 or left untreated (data not shown).

The typical effect of gating with the M1 and M2 markers is illustrated in Figure 1C and D for wheat plants treated with the dual reporter CHA0-mche/pM7100. The FL3-H and FL1-H histograms depict the distinct red and green fluorescence peaks, respectively, recorded for the approximately 85,000 particles (events) gated in zone R1 defined on the FSC-H/SSC-H density plot (Fig. 1C). Gating with the M1 marker indicates that more than $10 \%$ of these particles emit green fluorescence at levels that are not distinguishable from background fluorescence (Fig. 1C, FL1-H/FSC-H density blot) yet it remains unclear whether the particles represent dual-reporter cells that do not express the phlA-gfp fusion carried by pME7100, root particles, or contaminating nonfluorescent microorganisms. Therefore, the R1-gated 
data obtained for the same CHA0-mche/pME7100 sample were subjected to gating with the marker M2 to eliminate red background fluorescence (Fig. 1D). Data after gating with M2 correspond to $45 \%$ of the original particles contained within the R1 gate and represent mCherry tag-expressing Pseudomonas cells only. The relative GFP fluorescence of the mCherry-tagged cells is shown in the FL1-H/FSC-H density blot and the FL1-H histogram, respectively (Fig. 1D, left and middle panels). In the example, the mean green fluorescence value (geometric mean) per R1- and M2-gated particle is 96.97 and reflects the average phlA-gfp expression per CHA0-mche/pME7100 cell. An additional gating with the M1 marker discriminates between $\mathrm{CHA} 0$ $m c h e /$ pME7100 cells expressing the phlA-gfp reporter fusion and nonexpressing cells. In the example, a vast majority $(98.8 \%)$ of the cells expresses the DAPG biosynthetic gene at significant levels (Fig. 1D, FL1-H/FSC-H density blot).

No significant red fluorescence peak could be detected for $g f p$-expressing CHA0/pME7100 with the FL3-H detector (Fig. 1A) and, vice versa, no green fluorescence peak for mCherrylabeled CHA0-mche with the FL1-H detector (Fig. 1B), whereas both fluorescence peaks were readily distinguishable in the dual reporter CHA0-mche/pME7100 (Fig. 1C). This demonstrates that the two fluorescence signals do not significantly interfere with each other and can be separated effectively in the FACS analysis of cells of dual-labeled reporter strains. Additional fluorimetric analyses of batch cultures of CHA0mche/pME7100, CHA0-mche, and CHA0/pME7100 confirmed the clear separation of the green and red fluorescence signals (data not shown).
To specify the detection limits in the flow cytometric analysis of mCherry-tagged Pseudomonas cells, root washes from 5-day-old wheat plantlets that had been incubated for $20 \mathrm{~min}$ in differentially concentrated suspensions of CHA0-mche cells prepared from stationary phase cultures were analyzed by FACS. A minimal bacterial population density corresponding to $2 \times 10^{6} \mathrm{R} 1$ - and M2-gated particles (mCherry tag-expressing cells) per gram of root was required to obtain a red fluorescence peak that was clearly distinguishable from background fluorescence. The detection limit was not influenced by the presence of one of the GFP-based reporter plasmids in strain CHA0-mche (data not shown). A similar cell density on roots was also sufficient to obtain a clearly measurable green fluorescence peak for $g f p$-expressing reporter strains (data not shown).

The stability of expression of the mCherry tag during bacterial growth was assessed for strains CHA0-mche/pME7100 and CHA0-mche/pME7156 that were later used in experiments involving different cereal cultivars (discussed below). The mean red fluorescence per M2-gated particle (i.e., per mCherry tag-expressing Pseudomonas cell), determined in cultures growing in minimal glycerol-ammonium (OSGly) medium, was largely similar throughout the exponential and stationary growth phases (Table 2), indicating that expression of mcherry was constitutive in both strains. Nevertheless, a marked increase in the number of M2-gated particles was only visible during the transition from the late exponential to the stationary growth phase (Table 2), indicating that a significant fraction of exponential-phase Pseudomonas cells do not yet express the

Table 1. Bacterial strains, plasmids, and oligonucleotides used in this study

\begin{tabular}{|c|c|c|}
\hline $\begin{array}{l}\text { Strain, plasmid, or } \\
\text { oligonucleotide }\end{array}$ & Relevant characteristics or sequence $\left(5^{\prime} \rightarrow 3^{\prime}\right)^{y}$ & Reference or source \\
\hline \multicolumn{3}{|c|}{ Pseudomonas fluorescens } \\
\hline CHA0 & Wild type; biocontrol agent; $\mathrm{DAPG}^{+}, \mathrm{PLT}^{+}, \mathrm{PRN}^{+}, \mathrm{HCN}^{+}$ & Schnider-Keel et al. 2000 \\
\hline CHA0-mche & CHA0::att $\mathrm{Tn} 7-m c h e r r y ; \mathrm{Gm}^{\mathrm{r}}$ & This study \\
\hline \multicolumn{3}{|l|}{ Escherichia coli } \\
\hline DH5 $\alpha$ & Laboratory strain & Sambrook and Russell 2001 \\
\hline \multicolumn{3}{|l|}{ Plasmids } \\
\hline pME3280a & Carrier plasmid for $\mathrm{Tn} 7$ containing the mini-Tn7-Gm transposon; $\mathrm{Ap}^{\mathrm{r}} \mathrm{Gm}^{\mathrm{r}}$ & Schnider-Keel et al. 2000 \\
\hline pME6552 & Delivery plasmid for $\mathrm{P}_{t a c}$ promoter; $\mathrm{Km}^{\mathrm{r}}$ & C. Blumer \\
\hline pME7100 & $p h l A-g f p$ transcriptional fusion; reporter for DAPG biosynthetic gene expression in CHA0; $\mathrm{Tc}^{\mathrm{r}}$ & Baehler et al. 2005 \\
\hline pME7116 & prnA-gfp transcriptional fusion; reporter for PRN biosynthetic gene expression in $\mathrm{CHA} 0 ; \mathrm{Tc}^{\mathrm{r}}$ & Baehler et al. 2005 \\
\hline pME7144 & $\begin{array}{l}\text { pltA-gfp transcriptional fusion; reporter for PLT biosynthetic gene expression in CHA0; } \\
\text { pPROBE-NT with a } 0.9-\mathrm{kb} \text { HindIII-Bam HI fragment of pNAB1; } \mathrm{Km}^{\mathrm{r}}\end{array}$ & This study \\
\hline pME7156 & $\begin{array}{l}\text { hcnA-gfp transcriptional fusion; pPROBE-TT' with a 472-bp EcoRI-BamHI fragment containing } \\
\text { the } h c n A \text { promoter region from CHA0;Tc }\end{array}$ & This study \\
\hline pME9010 & mCherry-based promoter-probe vector derived of pPROBE'-gfp[AAV]; Km ${ }^{\mathrm{r}}$ & This study \\
\hline pME9011 & $\begin{array}{l}\text { hcnA-mcherry transcriptional fusion; pME9010 with the 472-bp EcoRI-BamHI fragment of } \\
\text { pME7156; } \mathrm{Km}^{\mathrm{r}}\end{array}$ & This study \\
\hline pME9012 & $\begin{array}{l}\text { phlA-mcherry transcriptional fusion; pME9010 with a 1.1-kb SmaI-BamHI fragment of } \\
\text { pME7100; } \mathrm{Km}^{\mathrm{r}}\end{array}$ & This study \\
\hline pME9407 & $\begin{array}{l}\text { Delivery plasmid for mini-Tn7-mcherry; pME3280a carrying mcherry placed under } \mathrm{P}_{t a c} \text { control; } \\
\mathrm{Ap}^{\mathrm{r}} \mathrm{Gm}^{\mathrm{r}}\end{array}$ & This study \\
\hline pMQ64-mChe & Delivery vector for mcherry; $\mathrm{Gm}^{\mathrm{r}}$ & D. K. Newman \\
\hline pNAB 1 & pBLS-II KS containing the pltA leader region of CHA0; $\mathrm{Ap}^{\mathrm{r}}$ & Péchy-Tarr et al. 2005 \\
\hline pPROBE'-gfp[AAV] & Promoter-probe vector based on an unstable GFP variant; $\mathrm{Km}^{\mathrm{r}}$ & Miller et al. 2000 \\
\hline pPROBE-TT & Promoter-probe vector based on stable GFP; $\mathrm{Tc}^{\mathrm{r}}$ & Miller et al. 2000 \\
\hline pPROBE-NT & Promoter-probe vector based on stable GFP; $\mathrm{Km}^{\mathrm{r}}$ & Miller et al. 2000 \\
\hline pUK21 & Cloning vector; $\mathrm{Km}^{\mathrm{r}}$ & Vieira and Messing 1991 \\
\hline pUX-BF13 & Helper plasmid encoding Tn7 transposition functions; R6K-replicon; Ap ${ }^{r}$ & Bao et al. 1991 \\
\hline \multicolumn{3}{|l|}{ Oligonucleotides ${ }^{\mathrm{z}}$} \\
\hline Mche1 & $\begin{array}{l}\text { ACGCGTCGACGTCTAACTAACTAAAGATTAACTTTATAAGGAGGAAAAACATATGG } \\
\text { TTTCCAAGGGCGAGGAG, SalI }\end{array}$ & This study \\
\hline Mche2 & CCCAAGCTTGTTATTTGTACAGCTCATCCATGCCACC, HindIII & This study \\
\hline Mche4 & CGGAATTCTTTAAGAAGGAGATATACATATGGTTTCCAAGGGCGAGGAG, EcoRI & This study \\
\hline Phcn 1 & GGAATTCTGAAAGCGATGTCCAGC, EcoRI & This study \\
\hline Phen2 & CGGGATCCGCTGAATATCGAAGTT, BamHI & This study \\
\hline
\end{tabular}


mCherry tag at a FACS-detectable level. In the stationary growth phase, M2-gated particles represented more than $90 \%$ of the total measured particles, indicating that the mCherry marker is detectable by FACS in most of the stationary-phase cells. A control experiment with CHA0-mche showed that the presence of the GFP-based reporters did not negatively affect mcherry expression in the dual-reporter strains (data not shown). The stability of mCherry expression by $\mathrm{CHA} 0-m c h e$
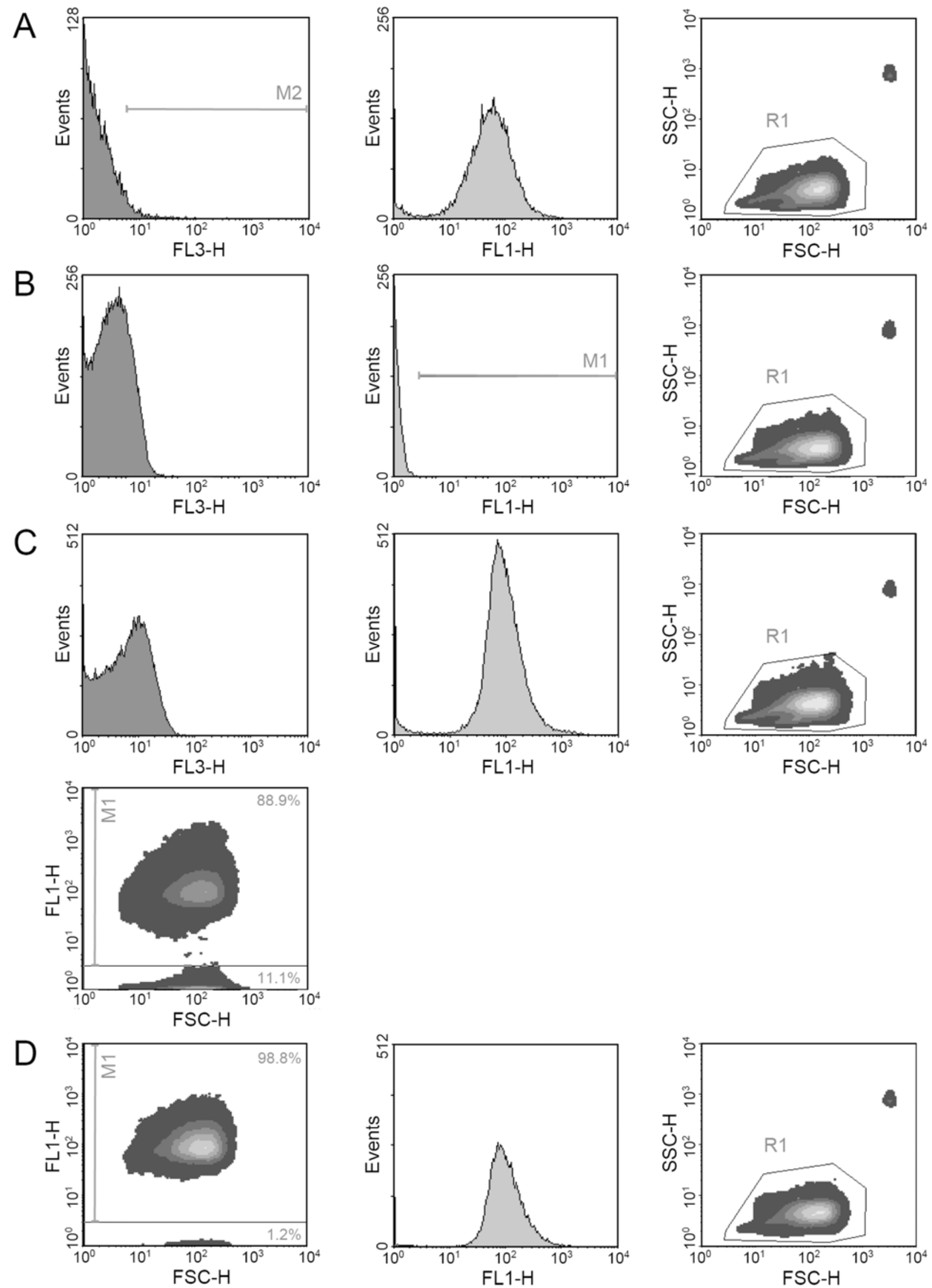
and CHA0-mche/pME7100 in OSGly medium was also evaluated by fluorimetry. The red fluorescence emitted by all cells varied little for both strains throughout the exponential growth phase, attaining 63,000 to 89,000 relative fluorescence units (RFU) for CHA0-mche and 56,000 to 71,000 RFU for CHA0mche/pME7100. The RFU values attained during stationary growth were approximately twice as high (data not shown).

Together, the calibration assays demonstrate that the red and green fluorescence signals emitted by the newly developed dualreporter strains can be readily detected and separated by FACSbased flow cytometry. The constitutively expressed mCherry tag makes it possible to distinguish inoculant cells from other rhizosphere bacteria and root particles present in analyzed samples. The GFP reporters carried by the same cells permit the monitoring of variations of antifungal gene expression in inoculant populations, most relevantly including the possibility to uncover the lack of antifungal gene expression in specific subpopulations.

\section{Differential expression of $\boldsymbol{P}$. fluorescens antifungal genes on roots of wheat.}

In the next series of experiments, the new $P$. fluorescens dual reporters CHA0-mche/pME7100, CHA0-mche/pME7116, CHA0-mche/pME7144, and CHA0-mche/pME7156 were used to determine expression levels of DAPG, PRN, PLT, and HCN biosynthetic genes, respectively, on the roots of the wheat $\mathrm{cv}$. Arina by the above FACS approach. After 5 days of incubation in the plant growth pouches, highly similar root colonization levels were attained by the four dual-reporter strains (Table 3), indicating that the different reporter fusions did not affect colonization capacity. The number of M2-gated particles, corresponding to mCherry tag-expressing Pseudomonas cells, was approximately $10^{9}$ per gram of roots and represented between 20 and $29 \%$ of the total particles detected by the flow cytometer. Inoculant densities on roots determined by plate counts were approximately 10 -fold lower and varied approximately $10^{8} \mathrm{CFU} / \mathrm{g}$ of roots (Table 3 ). The root colonization capacity of the $P$. fluorescens dual reporters was not influenced by the presence of the mcherry tag or the $g f p$ reporters, as determined by control treatments in which plants were inoculated with strains carrying only one of the constructs or an empty vector control (i.e., CHA0-mche, CHA0-mche/pPROBE-TT, CHA0/pME7100, and CHA0/pPROBE-TT) (data not shown). The Tn7 construct and the $g f p$-based reporter plasmids were highly stably maintained in P. fluorescens, as already known from previous assays (Baehler et al. 2005, 2006). The stability of the $p h l A-g f p, p r n A-g f p, p l t A-g f p$, or $h c n A-g f p$ reporters was not influenced by the presence of the mcherry tag in the dual- label strains and, at the end of the experiment, almost $100 \%$ of the cells in the different treatment replicates still carried the reporter plasmid.

The expression levels of the DAPG, PRN, PLT, and HCN biosynthetic genes on wheat roots varied considerably. High expression levels were recorded for the phlA-gfp and prnA-gfp fusions, which attained average relative fluorescence values of 75.1 and 59.3 per mCherry-tagged Pseudomonas cell, respectively (Table 3). By contrast, the wheat rhizosphere appeared to sustain pltA-gfp and hcnA-gfp expression to a considerably lesser extent, as illustrated by the marginal fluorescence levels of 1.4 and 2.2 per mCherry-tagged cell, respectively (Table 3 ). This is supported by the fact that the two reporter fusions were expressed at high levels (mean fluorescence values of 66.2 for pltA-gfp and 20.3 for $h c n A-g f p$ ) when the cells were grown to the early stationary phase in a minimal medium (Table 3 ). The poor expression of pltA and hcnA genes on wheat roots was further underscored by the fact that only a small fraction of the mCherry-tagged Pseudomonas cells expressed the respective $g f p$-based reporters at levels above background fluorescence (Table 3). In contrast, most of the inoculant cells (approxi-

Table 2. Expression of the mCherry cell tag in dual-labeled derivatives of Pseudomonas fluorescens $\mathrm{CHA} 0$ during batch growth in minimal medium ${ }^{\mathrm{w}}$

\begin{tabular}{|c|c|c|c|}
\hline Strain, growth phase & $\mathrm{OD}_{600}{ }^{\mathrm{x}}$ & $\begin{array}{l}\text { No. of gated } \\
\text { events } \\
\left(\times 10^{8} / \mathrm{ml}\right)^{y}\end{array}$ & $\begin{array}{c}\text { Relative mCherry } \\
\text { fluorescence per } \\
\text { gated event }^{\mathrm{z}}\end{array}$ \\
\hline \multicolumn{4}{|l|}{ CHA0-mche/pME7100 } \\
\hline Early exponential & $1.00 \mathrm{a}$ & $0.36 \mathrm{a}$ & $9.17 \mathrm{a}$ \\
\hline Late exponential & $2.85 \mathrm{~b}$ & $0.67 \mathrm{~b}$ & $10.08 \mathrm{a}$ \\
\hline Stationary & $4.10 \mathrm{c}$ & $5.20 \mathrm{c}$ & $23.15 \mathrm{~b}$ \\
\hline \multicolumn{4}{|l|}{ CHA0-mche/pME7156 } \\
\hline Early exponential & $1.07 \mathrm{a}$ & $0.21 \mathrm{a}$ & $8.38 \mathrm{a}$ \\
\hline Late exponential & $3.03 \mathrm{~b}$ & $0.39 \mathrm{ab}$ & $8.50 \mathrm{a}$ \\
\hline Stationary & $4.20 \mathrm{c}$ & $4.25 \mathrm{c}$ & $10.90 \mathrm{a}$ \\
\hline
\end{tabular}

${ }^{\mathrm{w}}$ Strains CHA0-mche/pME7100 (phlA-gfp) and CHA0-mche/pME7156 ( $h c n A-g f p)$ were grown in minimal glycerol-ammonium medium at $30^{\circ} \mathrm{C}$ and mcherry expression by the cells was recorded with the FL3-H detector of the FACSCalibur flow cytometer (Becton Dickonson Immunocytometry Systems, San Jose, CA, U.S.A.). Data represent the means of three replicates per treatment. Values in the same column followed by different letters are significantly different according to Tukey's test ( $P \leq$ 0.05).

${ }^{x}$ Optical density at $600 \mathrm{~nm}$.

${ }^{\mathrm{y}}$ Number of events (particles) per milliliter gated with the marker M2 to eliminate red background fluorescence, corresponding to Pseudomonas cells expressing the mCherry tag.

${ }^{\mathrm{z}}$ Relative red fluorescence per M2-gated event reflecting the average mcherry expression per Pseudomonas cell.

Fig. 1. Fluorescence-activated cell sorting analysis of the expression of a mcherry-based cell tag and a phlA-gfp reporter in Pseudomonas fluorescens CHA0 on the roots of the wheat cv. Arina. A, Analysis of a treatment inoculated with CHA0 carrying a phlA-gfp fusion on pME7100. Histograms show red (left panel) and green (middle panel) fluorescence recorded by the FL3-H and the FL1-H detector, respectively. The marker M2 set on the FL3-H channel allows for subtraction of the red background fluorescence noise. The smoothed gray-scale density plot (linear; $15 \%$ intervals) in the right panel shows the size and internal granularity of analyzed particles (events) detected by the forward scatter (FSC-H) and side scatter (SSC-H) detector, respectively. The zone R1 on the density plot encompasses particles of the size and granularity of Pseudomonas cells. Data shown in the FL3-H and FL1-H histograms are gated with R1 (31,986 events). Red fluorescent microspheres which were used to standardize the volume ( $2 \mu \mathrm{l})$ of the analyzed samples are visualized on the right top corner of the density plot. B, Analysis of a treatment inoculated with CHA0-mche carrying a chromosomal mcherry-based cell tag. Histograms show red and green fluorescence recorded by the FL3-H and the FL1-H detector, respectively. The marker M1 set on the FL1-H channel allows for subtraction of the green background fluorescence. Data shown in histograms are gated with R1 defined on the FSC-H/SSC-H density plot (55,791 events in $2 \mu \mathrm{l})$. C, Analysis of a treatment inoculated with the dual reporter CHA0-mche/pME7100 carrying a mCherry cell tag and a phlA-gfp fusion on pME7100. Histograms show red and green fluorescence recorded by the FL3-H and the FL1-H detector, respectively. The density plot below the FL3-H histogram shows the size and green fluorescence of analyzed events detected by the FSC-H and the FL1-H detector, respectively. The percentage of green fluorescent (gated with M1) and nonfluorescent events is indicated. Data shown are gated with R1 defined on the FSC-H/SSC-H density plot (85,274 gated events in $2 \mu \mathrm{l}$ ). D, The same analysis of the CHA0-mche/pME7100 sample as in panels $\mathrm{C}$ after subtraction of the red background fluorescence by gating with marker M2, in order to monitor phlA-gfp expression in mCherry-tagged Pseudomonas cells only. The M1 gate shown in the FSC-H/FL1-H density plot allows for separation of gfpexpressing from nonexpressing cells. Data after gating with M2 correspond to 37,996 particles (events) in $2 \mu \mathrm{l}$ (i.e., $44.6 \%$ of the events gated with R1). Mean green fluorescent protein (GFP) fluorescence value per R1- and M2-gated particle (i.e., mCherry-tagged cell) is 96.97 in the example shown. 
mately 90\%) expressed the phlA and prnA reporters on the roots, and virtually all cells expressed the four reporters in batch culture (Table 3), suggesting that the wheat rhizosphere favors the expression of DAPG and PRN biosynthetic genes. To determine whether the poor $h c n A$ and pltA expression levels per cell on roots were due to the high percentage of nonexpressing cells, we also calculated the mean GFP fluorescence per mCherry-tagged cell following gating with the M1 marker (i.e., following exclusion of those inoculant cells that do not express the $g f p$ reporters). This was not the case, because values for the M1-gated inoculant cells were 6.1 and 7.7 for the pltA-gfp and hcnA-gfp reporters, respectively (i.e., not much higher than those obtained for nongated cells) (Table 3 ).

The variation of GFP reporter expression among the mCherry-tagged cells was estimated on the basis of the average FL1-H histogram dispersion (standard deviation) recorded for the M2-gated events. Mean standard deviations for the four replicates were 155.2 and 135.3 for $p h l A-g f p$ and $p r n A-g f p$ reporters, respectively, and were significantly different $(P=$ 0.05 ) from the mean standard deviations of 6.5 and 14.1 for the $p l t A-g f p$ and $h c n A-g f p$ reporters, respectively. When regarded in relation to the mean GFP fluorescence per mCherrytagged cell (Table 3), these values highlight the high variability in levels of antifungal gene expression among cells of an inoculant population. The heterogeneity of antifungal gene expression could also be detected when examining wheat root samples by epifluorescence microscopy and is exemplified in Figure $2 \mathrm{~A}$ for expression of the phlA-gfp reporter in CHA0-mche cells. A majority of the dual-reporter cells in the microcolony show a uniform expression of the mCherry tag (Fig. 2A1), whereas they exhibit a considerable variability in the expression of the GFP-based reporter (Fig. 2A2 and A3).

In summary, these experiments demonstrate that the $P$. fluorescens dual-reporter strains are suitable for quantifying and correlating root colonization and antifungal gene expression levels in the rhizosphere. Results suggest that the rhizosphere of wheat favors the expression of DAPG and PRN biosynthetic genes whereas it appears to be markedly less conducive to the expression of PLT and HCN biosynthetic genes. The experiments also highlight the considerable variation in antifungal gene expression among the individual cells of the inoculant population.

\section{Expression of DAPG and HCN biosynthetic genes on roots of different cereal cultivars.}

We then chose to investigate in more detail the expression of the $p h l A-g f p$ and $h c n A-g f p$ reporter fusions identified as antifungal genes that were expressed at high and low levels, respectively, on roots of the wheat cv. Arina. Expression levels of the two reporter fusions were monitored in the rhizosphere of a series of other cereals, including different cultivars of wheat, spelt, and triticale, and related to root colonization capacity to test whether the dual reporters were sensitive enough to detect plant influences at the level of the cultivar.

Root colonization levels of the DAPG reporter strain CHA0$m c h e /$ pME7100 were clearly different in the rhizosphere of certain cereal cultivars. The highest colonization levels could be detected on roots of the wheat cv. Probus and the spelt cv. Altgold (approximately $8 \times 10^{8}$ gated cells/g), whereas root colonization levels were significantly lower on the triticale cv. Prader (Table 4). These differences in root colonization levels could be confirmed by selective CFU counts which, as already observed in the above experiments (Table 3), were approximately 10 -fold lower than the counts of the mCherry-tagged cells made with the flow cytometer (data not shown). Overall, a highly significant correlation between the CFU counts $(\mathrm{CFU} / \mathrm{ml})$ and the flow cytometer counts $(\mathrm{M} 2$-gated cells/ml) in samples from all root washes could be determined following a linear regression analysis $\left(y=0.156 x+1 \times 10^{7} ; P=0.001\right)$. There were subtle differences in expression levels of the $g f p$ based reporter for DAPG biosynthetic gene expression. The relative GFP fluorescence per mCherry-tagged cell of $P$. fluorescens $\mathrm{CHA0}$ was highest on the roots of the spelt cvs. Altgold and Frankenkorn and, in general, was lower on the roots of the three triticale cultivars tested (Table 4). In the case of the triticale cv. Triamant, which exhibited the lowest $p h l A-g f p$ expression levels, the difference with the two spelt cultivars was significant. When considering the total GFP fluorescence per root (i.e., with colonization levels taken into account), the cv. Altgold promoted approximately two times higher expres-

Table 3. Expression of green fluorescent protein (GFP)-based reporters for 2,4-diacetylphloroglucinol (DAPG), pyrrolnitrin (PRN), pyoluteorin (PLT), and hydrogen cyanide (HCN) biosynthetic genes carried by mCherry-tagged Pseudomonas fluorescens CHA0-mche on the roots of wheat and in vitro ${ }^{\mathrm{r}}$

\begin{tabular}{|c|c|c|c|c|c|c|c|c|}
\hline \multirow[b]{2}{*}{ Reporter $^{s}$} & \multicolumn{3}{|c|}{ Number per gram of $\operatorname{root}\left(\times 10^{8}\right)$} & \multicolumn{3}{|c|}{ Relative GFP fluorescence } & \multicolumn{2}{|c|}{ Expression $^{\mathrm{Z}}$} \\
\hline & Events $^{t}$ & mCherry $^{u}$ & $\mathrm{CFU}^{\mathrm{v}}$ & Cell $^{w}$ & $\operatorname{Root}^{x}$ & In vitro $^{y}$ & $\%$ on roots & $\%$ in vitro \\
\hline phlA-gfp & $45.2 \mathrm{a}$ & $10.5 \mathrm{a}$ & $1.02 \mathrm{a}$ & 75.1 & 81.0 & 118.7 & $89.5 \mathrm{a}$ & $99.9 \mathrm{a}$ \\
\hline$p r n A-g f p$ & $55.6 \mathrm{a}$ & $10.9 \mathrm{a}$ & $0.91 \mathrm{a}$ & 59.3 & 67.2 & 22.1 & $90.6 \mathrm{a}$ & $99.8 \mathrm{a}$ \\
\hline$p l t A-g f p$ & $47.8 \mathrm{a}$ & $9.6 \mathrm{a}$ & $0.79 \mathrm{a}$ & 1.4 & 1.6 & 66.2 & $4.6 \mathrm{c}$ & $99.5 \mathrm{a}$ \\
\hline hcnA-gfp & $54.4 \mathrm{a}$ & $15.7 \mathrm{a}$ & $1.62 \mathrm{a}$ & 2.2 & 3.1 & 20.3 & $17.1 \mathrm{~b}$ & $99.6 \mathrm{a}$ \\
\hline
\end{tabular}

${ }^{\mathrm{r}}$ Seedlings of the wheat cv. Arina were inoculated with strain CHA0-mche carrying reporter plasmid pME7100 (phlA-gfp), pME7116 (prnA-gfp), pME7144 ( $p l t A-g f p$ ), or pME7156 ( $h c n A-g f p$ ) and grown in plant growth pouches. After 5 days, bacterial cells in root washes were analyzed by fluorescence-activated cell-sorting-based flow cytometry, recording expression of the GFP reporter and the mCherry tag with the FL1-H and the FL3-H detector, respectively. Means of four replicates per treatment are presented. Values in the same column followed by different letters are significantly different according to Tukey's test $(P \leq 0.05)$. The experiment was repeated once with similar results (data not shown).

s Reporter fusion.

${ }^{\mathrm{t}}$ Total number of analyzed particles per fresh root weight.

${ }^{u}$ Number of Pseudomonas cells expressing the mCherry tag (i.e., events gated with the M2 marker to eliminate red background fluorescence) per fresh root weight.

${ }^{v}$ Number of culturable cells carrying the mCherry tag as determined by serial plating on nutrient agar plates containing gentamycin.

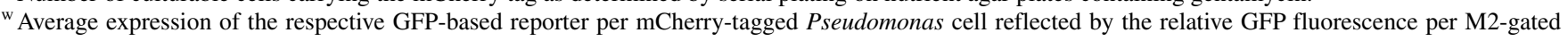
event.

${ }^{\mathrm{x}}$ Relative GFP fluorescence per gram of root $\left(\times 10^{9}\right)$ reflects the total expression of the respective GFP-based reporter by all mCherry tag-expressing Pseudomonas cells per fresh root weight, calculated as the (total number of mCherry-tagged cells $\times$ average GFP expression per mCherry-tagged cell) per gram of root.

${ }^{y}$ Average expression of the respective GFP-based reporter per mCherry-tagged cell recorded during the early stationary growth phase (optical density at 600 $\mathrm{nm}$ of approximately 3.2 ) in minimal glycerol-ammonium medium.

${ }^{\mathrm{z}}$ Percentage of mCherry-tagged Pseudomonas cells (M2-gated events) expressing the respective GFP-based reporter on roots or in vitro was calculated after gating with the marker M1, which allowed us to distinguish $g f p$-expressing from nonexpressing cells. 
sion levels than the other spelt cultivars and approximately fourfold higher levels than all three triticale cultivars (Table 4). The observed differences were significant at $P=0.05$. A high percentage $(\geq 90 \%)$ of the mCherry-tagged Pseudomonas cells expressed the GFP reporter above background fluorescence levels (Table 4), indicating that not only the root environment of wheat (as shown above) but also that of other cereals is conducive to the expression of DAPG biosynthetic genes. In the rhizosphere of the triticale Triamant, $85.9 \%$ of the mCherrytagged pseudomonads expressed the reporter, which was a significantly lower percentage than in all other cereals (Table 4).

The highest colonization levels of the $\mathrm{HCN}$ gene expression reporter strain CHA0-mche/pME7156 could again be observed on the roots of the spelt cv. Altgold (i.e., $7.1 \times 10^{8}$ cells expressing the mCherry tag per gram of root) (Table 5). Root colonization levels on Altgold were significantly higher than those on most of the other cereal cultivars that attained a level of approximately $2.5 \times 10^{8}$ cells/g of roots, except for the wheat cv. Probus and the triticale cv. Prader (Table 5). Similarly as for the DAPG biosynthetic genes, the rhizosphere of Altgold also promoted the highest expression levels for HCN biosynthetic genes. The relative GFP fluorescence exhibited by the hcnA-gfp fusion per mCherry-tagged pseudomonad cell attained a value of 4.53 and was more than two times higher than that for all other cereal cultivars, except for the triticale Prader that attained a value of 3.43 (Table 5). When taking root coloniza- tion levels into account, the total GFP fluorescence per gram of root exhibited by the dual-reporter strain in the rhizosphere of Altgold was even 3.6 to 7.6 times higher than that of the other cultivars, except Prader (Table 5). In general, the percentage of mCherry-tagged cells expressing the hcnA-gfp reporter varied between approximately 20 and $50 \%$ (Table 5), which was markedly lower than for the $p h l A-g f p$ reporter which was expressed by most of the cells (Table 4). Remarkably, cvs. Altgold and Prader, which best promoted hcnA gene expression, also harbored the highest percentage of cells expressing the GFP-based reporter (i.e., 48 and 45\%, respectively) (Table 5). This is in marked contrast to the wheat cv. Probus which, albeit favoring higher colonization levels than most of the other cereal cultivars, sustained $h c n A-g f p$ expression in only $19 \%$ of the mCherry-tagged cells.

Together, these experiments illustrate that the FACS-based flow cytometric approach in combination with the dual-reporter strains is sensitive enough to detect subtle variations in antifungal gene expression and root colonization capacity of a Pseudomonas inoculant in response to specific cereal genotypes.

\section{Development of mCherry-based reporters of antifungal gene expression.}

In addition to employing mcherry expressed from a constitutive promoter as a cell tag, we also attempted to use it as a reporter for monitoring antifungal gene expression. The aim
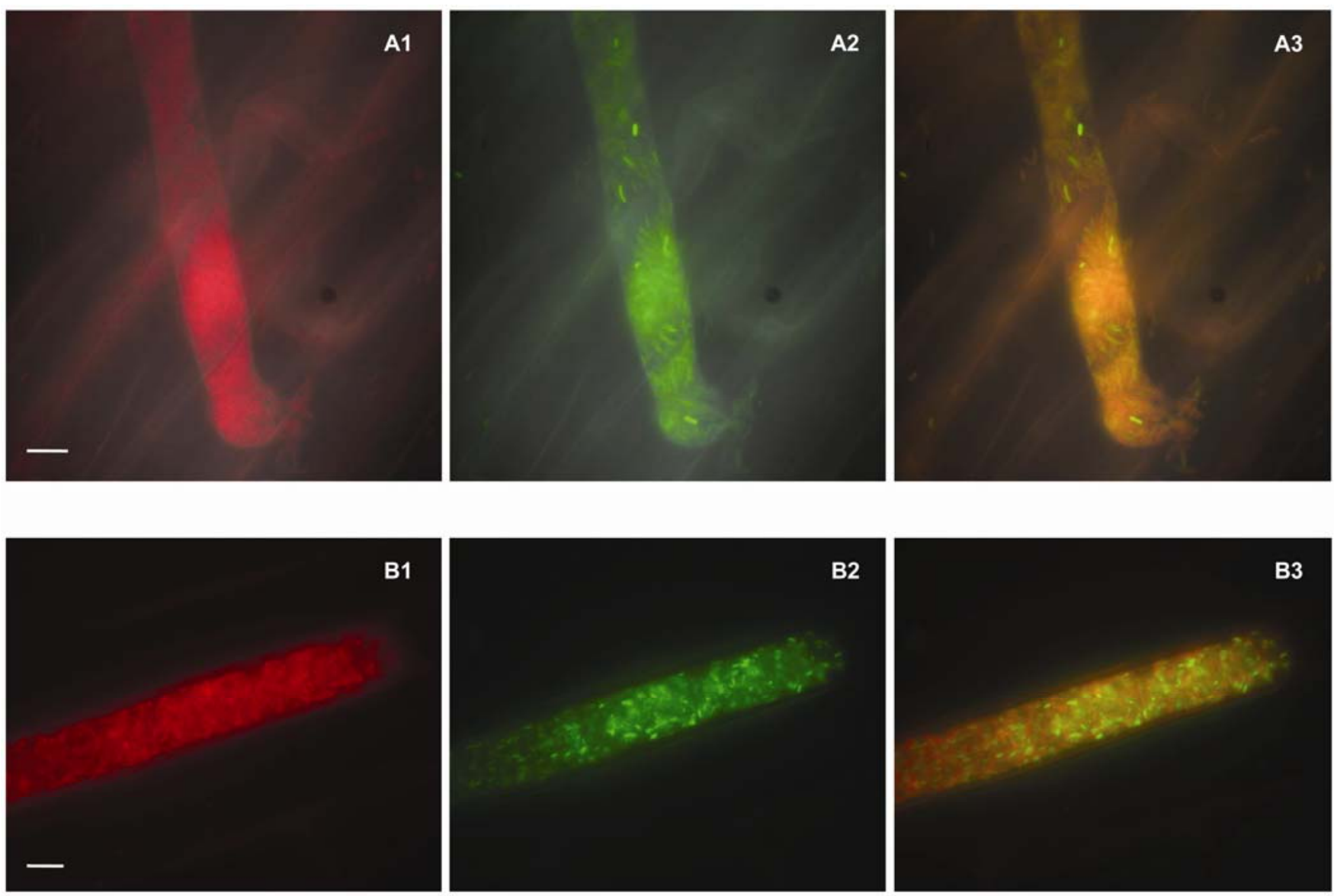

Fig. 2. In situ antifungal gene expression of Pseudomonas fluorescens $\mathrm{CHA} 0$ on wheat roots visualized by epifluorescence microscopy using green fluorescent protein (GFP)- and mCherry-based reporter constructs. Size bars represent $10 \mu \mathrm{m}$. A1-A3, Microcolony of the mCherry-GFP-based dual-label reporter strain CHA0-mche/pME7100 on a root hair. A1, Visualization of the mCherry cell tag expressed by the reporter cells; A2, expression of the GFP-based reporter of the 2,4-diacetylphloroglucinol (DAPG) biosynthetic gene phlA (pME7100) by the same cells; and A3, overlay of panels A1 and A2 to highlight the differential phlA-gfp expression levels in individual P. fluorescens cells. B1-B3, Expression of DAPG and hydrogen cyanide (HCN) biosynthetic genes in a microcolony consisting of a mixed population of the two reporter strains CHA0/pME9012 and CHA0/pME7156 5 days after inoculation at a ratio of 1:1. Visualization of B1, the phlA-mcherry fusion carried by pME9012; B2, the hcnA-gfp fusion carried by pME7156; and B3, overlay of panels B1 and B2. 
was to use GFP- and mCherry-based constructs to monitor, in parallel, the relative expression levels of two antifungal genes in strain mixtures. For this purpose, we constructed the mCherry-based promoter probe vector pME9010 which served to clone the mcherry gene under the control of the promoters of the DAPG or HCN biosynthetic genes, producing the phlAmcherry and hcnA-mcherry reporter plasmids pME9012 and pME9011, respectively (Table 1). We then tested the reporter plasmids in mixed populations on wheat roots in complementary combinations with reporter strains carrying the hcnA-gfp or phlA-gfp fusions on pME7156 and pME7100, respectively. FACS analyses of root washes from wheat plants inoculated with these strain mixtures revealed that the red fluorescence signal emitted by the mcherry-based reporters was too faint to allow for reliable quantification and separation from the GFP signal (data not shown). However, the new mcherry reporters were a suitable tool for visualizing in situ antifungal gene expression by fluorescence microscopy. A representative picture visualizing the simultaneous expression of a phlA-mcherry fusion and an hcnA-gfp fusion in a microcolony consisting of a mixed population of the $P$. fluorescens reporters CHA0/pME9012 and CHA0/pME7156 is shown in Figure 2B. Thus, the newly developed mcherry-based reporters may be a useful complement to the $g f p$ reporters in microscopic studies of expression patterns of multiple antibiotic genes during root colonization by $P$. fluorescens.

Table 4. Expression of a $p h l A-g f p$ reporter fusion carried by mCherrytagged Pseudomonas fluorescens CHA0 on the roots of different cereal cultivars $^{\mathrm{v}}$

\begin{tabular}{lcccc}
\hline & \multicolumn{4}{c}{$\begin{array}{c}\text { Relative GFP } \\
\text { fluorescence }\end{array}$} \\
\cline { 3 - 4 } Cereal, cultivar & No. of cells ${ }^{\mathbf{w}}$ & Cell $^{\mathbf{x}}$ & Root $^{\mathbf{y}}$ & Expression $(\%)^{\mathbf{z}}$ \\
\hline Wheat & & & & \\
Arina & $7.09 \mathrm{ab}$ & $87.4 \mathrm{ab}$ & $64.0 \mathrm{ab}$ & $97.3 \mathrm{a}$ \\
Probus & $8.35 \mathrm{a}$ & $82.4 \mathrm{ab}$ & $68.4 \mathrm{ac}$ & $97.0 \mathrm{a}$ \\
Cimetta & $6.90 \mathrm{ab}$ & $85.1 \mathrm{ab}$ & $60.1 \mathrm{ab}$ & $96.5 \mathrm{a}$ \\
Zinal & $5.15 \mathrm{ab}$ & $83.4 \mathrm{ab}$ & $43.1 \mathrm{ab}$ & $95.3 \mathrm{a}$ \\
Spelt & & & & \\
Oberkulmer & $4.06 \mathrm{ab}$ & $81.3 \mathrm{ab}$ & $33.8 \mathrm{bc}$ & $93.2 \mathrm{a}$ \\
Frankenkorn & $3.99 \mathrm{ab}$ & $91.4 \mathrm{ac}$ & $38.2 \mathrm{bc}$ & $95.2 \mathrm{a}$ \\
Altgold & $7.99 \mathrm{ac}$ & $101.7 \mathrm{a}$ & $80.5 \mathrm{a}$ & $97.3 \mathrm{a}$ \\
Triticale & & & & \\
Triamant & $3.54 \mathrm{bc}$ & $59.0 \mathrm{~b}$ & $22.9 \mathrm{~b}$ & $85.9 \mathrm{~b}$ \\
Bedretto & $3.36 \mathrm{bc}$ & $65.3 \mathrm{bc}$ & $21.8 \mathrm{bc}$ & $89.9 \mathrm{ab}$ \\
Prader & $2.69 \mathrm{~b}$ & $76.8 \mathrm{ab}$ & $22.7 \mathrm{~b}$ & $92.7 \mathrm{ab}$ \\
\hline
\end{tabular}

${ }^{v}$ Cereal seedlings were inoculated with strain CHA0-mche/pME7100 and grown in plant growth pouches. After 5 days, bacterial cells in root washes were analyzed by fluorescence-activated cell-sorting-based flow cytometry, recording $p h l A-g f p$ reporter and mcherry tag expression in the FL1-H and FL3-H channels, respectively. Data represent the means from three independent repetitions of the same experimental setup, with three replicates (growth pouches containing three plants) per treatment in each experiment. Data of the individual experiments could be pooled following an analysis of variance of experiment-treatment interactions. Values in the same column followed by different letters are significantly different according to Tukey's test $(P \leq 0.05)$.

${ }^{w}$ Number of mCherry-tagged cells per gram of root $\left(\times 10^{8}\right)=$ number of events gated with the marker M2 to eliminate red background fluorescence, corresponding to Pseudomonas cells expressing the mCherry tag.

${ }^{x}$ Relative green fluorescent protein (GFP) fluorescence per M2-gated event, reflecting the average expression of the phlA-gfp reporter per mCherry tag-expressing Pseudomonas cell.

${ }^{\mathrm{y}}$ Relative GFP fluorescence per gram of root $\left(\times 10^{9}\right)$, reflecting the total expression of the $p h l A$-gfp reporter by all mCherry tag-expressing Pseudomonas cells per fresh root weight.

${ }^{\mathrm{z}}$ Percentage of mCherry-tagged Pseudomonas cells (M2-gated events) expressing the $p h l A-g f p$ reporter fusion was calculated following gating with the marker M1, which allowed discrimination of $g f p$-expressing from nonexpressing cells.

\section{DISCUSSION}

The recent development of monitoring tools based on autofluorescent proteins has greatly facilitated the in situ study of bacterial behavior and function on plant roots. Autofluorescent proteins with distinct fluorescent spectra are of particular interest because they can be combined to measure different bacterial characteristics simultaneously. In the present study, we coexpressed reporters based on GFP and the monomeric DsRed variant mCherry to simultaneously visualize and quantify root colonization and antifungal gene expression by the biocontrol pseudomonad CHA0. We have demonstrated previously that levels of expression of GFP-based reporter fusions to DAPG, PLT, and PRN biosynthetic genes adequately reflect production of these antifungal compounds in P. fluorescens (Baehler et al. 2005). Dual labeling of cells with pairs of green and red fluorescent proteins has been reported before for other environmental bacteria; however, combinations of GFP with DsRed (Nancharaiah et al. 2003; Steidle et al. 2001) and of GFP with the DsRed derivative mRFP1 (Dulla and Lindow 2008) were used in those studies. Prior to using mCherry in our studies, we tested a series of DsRed variants as possible partners for combined use with GFP in P. fluorescens CHA0, including DsRed, DsRed2, DsRed-Express, DsRed.T3_S4T, and mRFP1 (Larrainzar et al. 2005; Shaner et al. 2004; Sörensen et al. 2003); however, none of them appeared to be suited for use as a cell tag or reporter of antifungal gene expression in our flow cytometric investigations (Baehler 2005). Remarkably,

Table 5. Expression of an $h c n A-g f p$ reporter fusion carried by mCherrytagged Pseudomonas fluorescens CHA0 on the roots of different cereal cultivars $^{\mathrm{v}}$

\begin{tabular}{|c|c|c|c|c|}
\hline \multirow[b]{2}{*}{ Cereal, cultivar } & \multirow[b]{2}{*}{ No. of cells ${ }^{w}$} & \multicolumn{2}{|c|}{$\begin{array}{c}\text { Relative GFP } \\
\text { fluorescence }\end{array}$} & \multirow[b]{2}{*}{ Expression $(\%)^{z}$} \\
\hline & & Cell $^{x}$ & $\operatorname{Root}^{\mathrm{y}}$ & \\
\hline \multicolumn{5}{|l|}{ Wheat } \\
\hline Arina & $2.74 \mathrm{a}$ & $2.03 \mathrm{a}$ & $0.56 \mathrm{a}$ & $22.4 \mathrm{ab}$ \\
\hline Probus & $4.65 \mathrm{ab}$ & $1.93 \mathrm{a}$ & $1.01 \mathrm{a}$ & $19.0 \mathrm{a}$ \\
\hline Cimetta & $2.15 \mathrm{a}$ & $2.15 \mathrm{a}$ & $0.48 \mathrm{a}$ & $21.3 \mathrm{ab}$ \\
\hline Zinal & $2.78 \mathrm{a}$ & $2.20 \mathrm{a}$ & $0.62 \mathrm{a}$ & $25.0 \mathrm{ab}$ \\
\hline \multicolumn{5}{|l|}{ Spelt } \\
\hline Oberkulmer & $2.63 \mathrm{a}$ & $2.15 \mathrm{a}$ & $0.58 \mathrm{a}$ & $24.2 \mathrm{ab}$ \\
\hline Frankenkorn & $2.80 \mathrm{a}$ & $2.13 \mathrm{a}$ & $0.60 \mathrm{a}$ & $26.8 \mathrm{ab}$ \\
\hline Altgold & $7.10 \mathrm{~b}$ & $4.53 \mathrm{~b}$ & $3.64 \mathrm{~b}$ & $48.3 \mathrm{c}$ \\
\hline \multicolumn{5}{|l|}{ Triticale } \\
\hline Triamant & $2.33 \mathrm{a}$ & $2.25 \mathrm{a}$ & $0.55 \mathrm{a}$ & $27.6 \mathrm{ab}$ \\
\hline Bedretto & $2.56 \mathrm{a}$ & $2.42 \mathrm{a}$ & $0.68 \mathrm{a}$ & $27.8 \mathrm{abc}$ \\
\hline Prader & $4.96 \mathrm{ab}$ & $3.43 \mathrm{ab}$ & $1.69 \mathrm{ab}$ & $45.3 \mathrm{bc}$ \\
\hline
\end{tabular}

${ }^{v}$ Seedlings were inoculated with strain CHA0-mche/pME7155 and after 5 days bacterial cells in root washes were analyzed by fluorescence-activated cell-sorting-based flow cytometry, recording hcnA-gfp reporter and mcherry tag expression in the FL1-H and FL3-H channels, respectively. Values represent the means calculated from pooled data from two independent repetitions of the same experimental setup, with three replicates per treatment in each experiment. Values in the same column followed by different letters are significantly different according to Tukey's test $(P \leq$ $0.05)$.

${ }^{\mathrm{w}}$ Number of mCherry-tagged cells per gram of $\operatorname{root}\left(\times 10^{8}\right)=$ number of events gated with the marker M2 to eliminate red background fluorescence, corresponding to Pseudomonas cells expressing the mCherry tag.

${ }^{x}$ Relative green fluorescent protein (GFP) fluorescence per M2-gated event, reflecting the average expression of the $h c n A-g f p$ reporter per mCherry tag-expressing Pseudomonas cell.

${ }^{y}$ Relative GFP fluorescence per gram of root $\left(\times 10^{9}\right)$, reflecting the total expression of the $h c n A-g f p$ reporter by all mCherry tag-expressing Pseudomonas cells per fresh root weight.

${ }^{\mathrm{z}}$ Percentage of mCherry-tagged Pseudomonas cells (M2-gated events) expressing the $h c n A-g f p$ reporter fusion was calculated following gating with the marker M1, which allowed discrimination of $g f p$-expressing from nonexpressing cells. 
although mCherry is widely applied as a marker for protein localization, up to now only relatively few studies have made use of it as a cell tag or reporter of gene expression in bacteria. In a microscopy approach, Tecon and associates (2009) used mCherry as a cell tag in a dual-label Burkholderia strain carrying a GFP-based reporter for sensing the bioavailability of polycyclic aromatic hydrocarbons in contaminated soil. mCherry also served as a reporter of gene expression in a Photorhabdus insect infection model (Münch et al. 2008).

We provide here a relatively robust methodology which combines novel GFP-mCherry reporter pairs with FACS for studying biocontrol pseudomonad-crop interaction at the single-cell level. Previous studies have demonstrated the usefulness of FACS for in situ monitoring of bacterial gene expression on plant surfaces (de Werra et al. 2008; Yang et al. 2008). The technique provides several advantages. First, it permits the study of a whole bacterial population and its heterogeneity in great detail because recorded information is available for each single cell. Second, a large number of cells can be easily monitored within a short period of time. Third, the sensitivity of detection is significantly improved compared with fluorescence microscopy or fluorimetry. The dual-label technique relying on two distinct, readily FACS-separable autofluorescent proteins in the same cell provides a substantial advance over the previous single-reporter strategy that relied on the same GFP reporter for following antifungal gene expression and inoculant identification (de Werra et al. 2008). A major drawback of the previous method was that it did not permit the detection of low- or non-expressing inoculant cells. The new dual-reporter approach now allows us to indicate the overall heterogeneity of antifungal gene expression within a bacterial population on roots by analyzing subpopulations that do or do not express a gene of interest. To our knowledge, this is the first study detecting pseudomonad subpopulations that do not express a specific plant-beneficial gene under rhizosphere conditions. Also, our work adds a further example to the rare studies that combined green and red fluorescent proteins for monitoring bacterial populations by flow cytometry (Hakkila et al. 2003; Sörensen et al. 2003).

Another apparent advantage of the constitutive mCherry tag in FACS analysis is that it allows the quantification of Pseudomonas populations on roots without need to resort to classical dilution-plating techniques. Population levels recorded by FACS were approximately 10 times higher than those determined by CFU counts (Table 3 ). This is in accordance with previous studies in which numbers of bacterial cells from root samples able to grow on media were markedly lower than those recorded by FACS (de Werra et al. 2008; Gamalero et al. 2004; Unge et al. 1999), highlighting the limits of CFU counting methods.

Patterns of antifungal gene expression in $P$. fluorescens $\mathrm{CHA} 0$ on wheat roots were found to be different from those observed in batch cultures where the reporters were expressed at high levels (Table 3). Expression levels of the DAPG and PRN reporters on wheat roots were high in contrast to expression levels of the PLT and HCN reporters, which were very low in this environment. Conditions of oxygen limitation are known to favor HCN gene expression in P. fluorescens (Laville et al. 1998). Thus, contrasting oxygen levels occurring in the rhizosphere and in culture media (Højberg et al. 1999) may provide an explanation for the relatively poor expression of $\mathrm{HCN}$ biosynthetic genes on wheat roots. Another possibility is that the rhizospheres of healthy cereals are not particularly conducive to $\mathrm{HCN}$ production, whereas diseased roots may promote production of the metabolite. Indeed, hcn genes were recently identified among those genes that were upregulated in a biocontrol pseudomonad following attack of wheat roots by a fungal pathogen (Barret et al. 2009). However, because cyanogenesis by $P$. fluorescens can also result in negative effects on plant growth (Rudrappa et al. 2008), still another possibility is that some plant hosts actively prevent root pseudomonads from producing deleterious levels of HCN. Similarly, a poor or lacking expression of PLT biosynthetic genes on roots of wheat in the present study or a range of other plants (triticale, barley, maize, tomato, and so on) in previous work (de Werra et al. 2008) suggests that many plant rhizospheres are not conducive to the production of this antifungal metabolite. This may explain why a significant role of PLT in biocontrol of root diseases so far could be detected only in select plant-pathogen systems (Maurhofer et al. 1994). Alternatively, high phl gene expression observed on roots of these plants (Tables 3 and 4) (de Werra et al. 2008) may have been deleterious to plt gene expression, as DAPG and PLT are known to exhibit a mechanism of mutual inhibition in strain CHA0 (Baehler et al. 2005; Schnider-Keel et al. 2000).

Our data suggest that unknown wheat-derived compounds present in the rhizosphere may specifically influence the production of individual antifungal metabolites in $P$. fluorescens. The signals mediating these plant-pseudomonad interactions are largely unknown; however, sugars and other organic compounds present in root exudates, particularly phenolics, may have a significant impact on antifungal gene expression (Badri and Vivanco 2009; de Werra 2009; Duffy and Défago 1999). Among several compounds of plant origin, indole-3-acetic acid stimulates DAPG gene expression, resorcinol represses PLT gene expression, and salicylate downregulates the expression of both antifungals in strain CHA0 (Baehler et al. 2005; de Werra 2009; Schnider-Keel et al. 2000).

The usefulness of our FACS-based method was confirmed by assays in which we took a closer look at plant genotypemediated effects on the expression of DAPG and HCN biosynthetic genes on roots of different wheat, triticale, and spelt cultivars (Tables 4 and 5). The approach proved sensitive enough to detect subtle differences in gene expression and root colonization levels exhibited by the dual-reporter inoculants. In particular, the spelt cv. Altgold sustained markedly higher levels of DAPG and HCN biosynthesis gene expression and root colonization by $P$. fluorescens $\mathrm{CHA} 0$ than most other cereal cultivars tested. Our data suggest that antifungal gene expression and colonization efficacy may be better sustained on roots of some cereal cultivars than on others. Depending on the cereal genotype, this may then translate into varying bacterial biocontrol efficacy. We suggest that differences in the quantity or composition of root exudates may account for the differences in biocontrol trait expression on the cereal cultivars. Our findings support and extend previous studies reporting plant genotype-specific impacts on root colonization, DAPG gene expression, and DAPG production by beneficial pseudomonads (Bergsma-Vlami et al. 2005; de Werra et al. 2008; Mazzola et al. 2004; Notz et al. 2001).

The dual-reporter FACS approach can be easily adapted for studying other biocontrol bacteria. In a pilot assay, we adapted it to monitor DAPG gene expression and root colonization by P. fluorescens Q2-87, a representative of another major genotypic group of plant-beneficial pseudomonads (Keel et al. 1996). Root populations of a Q2-87 dual reporter, quantified via FACS counts of the mCherry-tagged cells, were significantly smaller than those of CHAO on all cereals and were best sustained by spelt cultivars (data not shown). The variability of the percentage of cells expressing the strain-specific phlA-gfp reporter on roots of the different cereals was high, spanning from $79 \%$ on Probus to $96 \%$ on Oberkulmer. These observations further emphasize the occurrence of specific affinities between select cereal rhizospheres and biocontrol pseudomonads. 
In conclusion, the FACS-based technique exposed here constitutes a new and sensitive tool for detecting subtle variations in particular behaviors and functions of plant-associated bacteria in the rhizosphere, including detailed single-cell information about population heterogeneity. In the context of biocontrol, the approach may contribute knowledge that may serve in strategies aimed at optimizing plant protection by beneficial pseudomonads (e.g., by choosing the right bacterial partner for a given plant genotype).

\section{MATERIALS AND METHODS}

Bacterial strains, plasmids, and culture conditions.

The bacterial strains and plasmids used in this study are listed in Table 1. P. fluorescens and Escherichia coli strains were cultured at 30 and $37^{\circ} \mathrm{C}$, respectively, on nutrient agar (NA) plates, in Luria-Bertani (LB) broth, and in nutrient yeast broth (Péchy-Tarr et al. 2005, 2008). Antibiotics, when required, were added to the growth media at the following concentrations: ampicillin sodium salt, $100 \mu \mathrm{g} / \mathrm{ml}$; gentamycin sulfate, $10 \mu \mathrm{g} / \mathrm{ml}$; kanamycin sulfate, $25 \mu \mathrm{g} / \mathrm{ml}$; and tetracycline hydrochloride, $25 \mu \mathrm{g} / \mathrm{ml}$ for E. coli and $125 \mu \mathrm{g} / \mathrm{ml}$ for P. fluorescens strains. For plant inoculations, Pseudomonas strains were grown in LB broth without antibiotic addition to early exponential growth phase (i.e., to an optical density at $600 \mathrm{~nm}\left[\mathrm{OD}_{600}\right]$ of $0.3)$. Cells were harvested by centrifugation, washed twice, and suspended in sterile distilled water. The $\mathrm{OD}_{600}$ of the cell suspension was adjusted to 0.125 , corresponding to $10^{8}$ cells $/ \mathrm{ml}$.

\section{DNA manipulations.}

Chromosomal DNA of $P$. fluorescens was isolated as described previously (Schnider-Keel et al. 2000). Small- and largescale plasmid preparations were done with the cetyltrimethylammonium bromide method (Schnider-Keel et al. 2000) and the Jetstar 2.0 Plasmid Midiprep kit (Genomed, Basel, Switzerland), respectively. Standard techniques were used for restriction, agarose gel electrophoresis, isolation of DNA fragments from low-melting-point agarose gels, and ligation (Péchy-Tarr et al. 2008; Sambrook and Russell 2001). Restriction fragments were purified from agarose gels using the MinElute gel extraction or QIAquick gel extraction kits (Qiagen, Hombrechtikon, Switzerland), depending on the size of the fragment. Electrotransformation of bacterial cells with plasmid DNA was performed as described previously (Schnider-Keel et al. 2000). Polymerase chain reactions (PCR) in general were carried out using the GoTaq DNA polymerase kit (Promega, Dübendorf, Switzerland) following amplification protocols detailed previously (Baehler et al. 2005; Péchy-Tarr et al. 2008). All constructs involving PCR techniques were verified by sequence analysis. Nucleotide sequences were determined by Microsynth (Balgach, Switzerland). Sequences were analyzed with the Lasergene software package (version 8.0; DNASTAR, Inc., Madison, WI, U.S.A.).

\section{mCherry tagging of $P$. fluorescens.}

To tag P. fluorescens CHA0 with mCherry (Shaner et al. 2004), an mcherry variant gene expressed from the constitutive $\mathrm{P}_{\text {tac }}$ promoter was introduced as a single copy into the chromosome using a mini-Tn7 delivery system described previously (Schnider-Keel et al. 2000). To this end, the mcherry gene was amplified from plasmid pMQ64-mChe (provided by D. K. Newman, MIT) using primers Mche4 and Mche2 (Table 1). The 0.7-kb EcoRI-HindIII fragment obtained was cloned under $\mathrm{P}_{t a c}$ control in pME6552. A 1.6-kb SpeI-HindIII fragment from the resulting plasmid carrying the $\mathrm{P}_{t a c}-$ mcherry fusion was then cloned into the mini-Tn7-Gm carrier plasmid pME3280a (Schnider-Keel et al. 2000) opened with the same enzymes. The construct obtained, pME9407 (Table 1), and the Tn7 transposition helper plasmid pUX-BF13 (Bao et al. 1991) were co-electroporated (Baehler et al. 2006) into the recipient strain $\mathrm{CHA} 0$ to produce the mCherry-tagged derivative $\mathrm{CHA} 0$ mche.

\section{Construction of GFP- and mCherry-based reporters of antifungal gene expression.}

For the construction of the pltA-gfp reporter plasmid pME7144, a 0.9-kb HindIII-BamHI fragment containing the $P$. fluorescens CHA0 pltA promoter region was excised from pNAB1 (Péchy-Tarr et al. 2005) and inserted into the multiple cloning site (MCS) of the GFP-based promoter-probe vector pPROBE-NT (Miller et al. 2000). For the hcnA-gfp reporter pME7156, a 472-bp fragment containing the hcnA promoter (Laville et al. 1998) was amplified by PCR from the CHA0 chromosome using primers Phen1 and Phcn2 (Table 1). The EcoRI-BamHI-digested PCR product was cloned into pUK21 and, from there, into pPROBE-TT' (Miller et al. 2000), both opened with the same restriction enzymes, to produce pME7156.

To use mCherry as an alternative reporter of antifungal gene expression, we developed the mcherry-based promoter-probe vector pME9010. For this purpose, primers Mche1 and Mche2 (Table 1) served to PCR amplify the mcherry gene from pMQ64-mChe. The Mche1 primer equips the mcherry gene with a synthetic improved translation initiation region (TIR) designed on the basis of the TIR sequence of the GFP cassette plasmid pGreenTIR (Miller and Lindow 1997). The resulting 0.77-kb fragment was digested with SalI and HindIII and cloned into pUK21. The SalI-HindIII fragment was excised from this pUK21 derivative and inserted into vector pPROBE'gfp[AAV] (Miller et al. 2000) opened with the same enzymes, thereby substituting $g f p[\mathrm{AAV}]$ with the mcherry cassette and creating pME9010. To construct the hcnA-mcherry reporter plasmid pME9011, the 472-bp EcoRI-BamHI fragment containing the hcnA promoter from pME7156 was then cloned into the EcoRI-BamHI sites of pME9010. Similarly, a phlAmcherry reporter (pME9012) was generated by inserting a 1.1$\mathrm{kb}$ SmaI-BamHI fragment containing the CHA0 phlA promoter recruited from pME7100 (Baehler et al. 2005) into the MCS of pME9010.

\section{Assay for analysis of antifungal gene expression in vitro.}

For monitoring antifungal gene expression in vitro, CHA0mche carrying a phlA-gfp, prnA-gfp, pltA-gfp, or hcnA-gfp fusion (on plasmids pME7100, pME7116, pME7144, or pME7156, respectively) was grown in 50-ml Erlenmeyer flasks containing $10 \mathrm{ml}$ of OSGly (Baehler et al. 2005). For inoculation, suspensions of washed cells prepared from exponential-growth-phase cultures of the dual-reporter strains were adjusted to an $\mathrm{OD}_{600}$ of 0.05 and aliquots of $30 \mu$ were added per flask. Cultures were incubated at $30^{\circ} \mathrm{C}$ with orbital shaking at $180 \mathrm{rpm}$. At different growth phases, the relative green fluorescence of the GFP-based reporters per mCherry-tagged cell was recorded by FACS-based flow cytometry as described below. For testing the intensity and stability of expression of the constitutive mCherry tag during bacterial growth, the relative red fluorescence emitted by strains $\mathrm{CHAO}$-mche and CHA0$m c h e / p M E 7100$ grown in OSGly medium under the conditions described above was monitored by FACS. The expression of the GFP- and mCherry-based reporters was also followed by fluorimetry by measuring green fluorescence (excitation at 480 $\mathrm{nm}$ and emission at $520 \mathrm{~nm}$ ) and red fluorescence (excitation at $587 \mathrm{~nm}$ and emission at $661 \mathrm{~nm}$ ) intensities with a FLUOstar microplate reader (BMG Labtech GmbH, Offenburg, Germany) during exponential and stationary growth (Baehler et al. 2005). 
For each individual measurement, the green or red fluorescence value was divided by the corresponding $\mathrm{OD}_{600}$ value, giving the specific fluorescence of the cells expressed as RFU.

\section{Growth-pouch assay for monitoring}

antifungal gene expression on roots of different cereals.

In situ expression of antifungal genes and colonization levels of Pseudomonas strains were monitored on roots of the wheat cvs. Arina, Zinal, Probus, and Cimetta; the spelt cvs. Oberkulmer, Frankenkorn, and Altgold; and the triticale cvs. Triamant, Prader, and Bedretto using the abovementioned mCherry- and GFP-labeled dual-reporter strains. Untreated seed of each cereal cultivar (provided by F. Mascher, Agroscope Changins-Wädenswil, Switzerland) were surface-sterilized for $20 \mathrm{~min}$ in $4 \% \mathrm{NaClO}$ ( $\mathrm{vol} / \mathrm{vol}$ ) and then thoroughly rinsed with sterile distilled water. The husks of spelt were removed prior to this procedure. Seed were germinated on soft agar (Oxoid technical agar at $8.5 \mathrm{~g} /$ liter) for $48 \mathrm{~h}$ at $24^{\circ} \mathrm{C}$ in the dark. The sterile-grown cereal seedlings were then transferred to a standardized hydroponic plant assay system consisting of autoclaved cyg seed germination pouches $(18 \mathrm{~cm}$ high by $16.5 \mathrm{~cm}$ wide) (Mega International, West St. Paul, MN, U.S.A.) containing a paper wick moistened with $15 \mathrm{ml}$ of sterile distilled water. Three seedlings were placed into the trough formed by the paper wick in each growth pouch. Each seedling was inoculated with $1 \mathrm{ml}$ of a suspension containing $10^{8}$ washed cells prepared from exponential-growth-phase cultures of the $P$. fluorescens dual-reporter strains. A series of control treatments comprising wild-type CHA0, the mCherrytagged strain CHA0-mche (with or without pPROBE-TT as an empty vector control), and the GFP-expressing strain CHA0/pME7100 were included in the assays for setting the appropriate green and red fluorescence backgrounds for FACS analysis. Growth pouches were wrapped in aluminum foil to protect roots from light and were placed in a growth chamber set to $80 \%$ relative humidity for $16 \mathrm{~h}$ with light $\left(160 \mu \mathrm{E} / \mathrm{m}^{2} / \mathrm{s}\right)$ at $22^{\circ} \mathrm{C}$, followed by an 8 -h dark period at $18^{\circ} \mathrm{C}$. After incubation for 5 days, roots from each pouch were pooled in $10 \mathrm{ml}$ of autoclaved ultrapure water contained within a sterile $50-\mathrm{ml}$ Falcon tube. Tubes were vigorously agitated at $300 \mathrm{rpm}$ for 20 min to remove adhering bacteria from the roots. The resulting suspensions were transferred on ice and immediately analyzed by FACS. The fresh weight of the roots was measured and the number of culturable cells of the Pseudomonas strains was determined by CFU counting following plating serial dilutions of root washes on NA plates containing the appropriate selective antibiotics.

\section{FACS analysis.}

Expression levels of GFP- and mCherry-based reporters in $P$. fluorescens cells in samples from batch cultures and root washes were quantified with an FACSCalibur flow cytometer equipped with a $15-\mathrm{mW}$, air-cooled argon ion laser excitation light source (488 nm) (Becton-Dickinson, San Jose, CA, U.S.A.). Size and granularity (internal complexity) of bacterial cells and other particles were determined with the FSC-H and SSC-H detectors, respectively, and their green or red fluorescence emissions recorded with the FL1-H and FL3-H detectors, respectively, with signals being processed in log gain (de Werra et al. 2008). FSC-H signals were collected using a photodiode amplification factor of 10 and a threshold set to 253 . SSC-H signals were detected using a photomultiplier tube set at $350 \mathrm{~V}$ and a threshold of 72 . Green fluorescence was detected in the range of 515 to $545 \mathrm{~nm}$ (530/30 BP filter) with the FL1-H detector set at a photomultiplier tube voltage of 505 $\mathrm{V}$ and a threshold of 52. Red fluorescence was detected above $670 \mathrm{~nm}$ (670 LP filter) with the FL3-H detector set at $773 \mathrm{~V}$ and a threshold of 225. Prior to injection into the FACSCalibur system, each sample was spiked with flow check ruby red fluorescent microspheres (diameter of $6 \mu \mathrm{m}$; excitation range of 488 to $663 \mathrm{~nm}$ ) (Polysciences, Inc., Warrington, PA, U.S.A.) at final concentration of $2.5 \times 10^{2}$ microspheres $/ \mu$. The red microspheres (gated by size) were readily detectable with the FL3-H detector, and stopping data recording after 500 microsphere counts permitted us to standardize the analyzed volume of each sample to $2 \mu \mathrm{l}$.

The Becton-Dickinson CellQuest software (version 3.5) was used for data collection and the WinMDI software (version 2.8; Joseph Trotter) for data analysis. Gating was done by defining a zone on the FSC-H/SSC-H density plot encompassing particles of the size and granularity of Pseudomonas cells and by setting marker M2 above the background fluorescence noise (i.e., the autofluorescence emitted by root particles, bacterial cell fragments, and bacterial cells not expressing mCherry) on the FL3-H red fluorescence histogram. Control samples from growth media or roots inoculated with the GFPexpressing strain CHA0/pME7100 were used to identify the red background fluorescence noise. The red fluorescent events gated with the M2 marker correspond to Pseudomonas cells expressing the mCherry tag. The green fluorescence emitted by these cells, indicative of the expression of a GFP-based reporter of antifungal gene expression, was then analyzed on the FL1-H histogram of green fluorescence. The geometric mean of green fluorescence emitted by the gated events within this population was calculated with the WinMDI software. The mean fluorescence reflects the average expression of a GFPbased reporter of an antifungal gene per mCherry-tagged bacterial cell. The variation of GFP reporter expression among the mCherry-tagged cells, reflecting the heterogeneity of antifungal gene expression within the bacterial population, was estimated on the basis of the average FL1-H histogram dispersion (standard deviation) recorded for M2-gated events of a given treatment. The mCherry tag was also used to calculate root colonization levels of the bacterial inoculants by extrapolating the number of mCherry-tagged cells identified by FACS in the $2-\mu \mathrm{l}$ samples to the initial volume of the root washes $(10 \mathrm{ml})$ and the corresponding root weight. The percentage of cells expressing a specific GFP-based antifungal reporter fusion was calculated on the basis of the M1 gate. The M1 marker was defined above the background fluorescence noise emitted by CHA0-mche without $g f p$ reporter on the FL1-H histogram of green fluorescence.

\section{Epifluorescence microscopy.}

Colonization patterns of $P$. fluorescens dual reporters were monitored on roots of wheat cultivated for 5 days in growth pouches as described above. For microscopy, 1- to 2-cm long root pieces were mounted in a 1:1 ( $\mathrm{vol} / \mathrm{vol})$ mixture of filtersterile water and FluoroGuard antifade reagent (Bio-Rad, Reinach, Switzerland) on glass slides. Root samples were examined immediately with an Axioskop2 epifluorescence microscope (Zeiss, Germany) using a $\times 100$ objective (Plan-NEOFLUAR $\times 100 / 1.30$ oil; Zeiss). The microscope was equipped with filter sets for detecting GFP (470/40-nm excitation, 525/50-nm emission, beam splitter Q4951p), mCherry (545/30-nm excitation, 610/75-nm emission, beam splitter Q570lp), or both simultaneously with a longpass filter (470/40-nm excitation, LP 515$\mathrm{nm}$ emission, beam splitter FT510) (AF Analysentechnik, Tübingen, Germany). Images were taken with a SPOT RT-KE monochrome camera (Diagnostic Instruments, Sterling Heights, MN, U.S.A.) and analyzed with the MetaVue software (version 6.1r5; Universal Imaging Corporation, Downingtown, PA, U.S.A.). Images of dual-color reporter cells were taken individually for GFP and mCherry fluorescence signals 
and then combined using the layer functions of the Photoshop CS imaging software (Adobe Systems, Inc., San Jose, CA, U.S.A.).

\section{Statistical analysis.}

Statistical analyses were carried out using the program GraphPad Prism (version 5; GraphPad Software, Inc., La Jolla, CA, U.S.A.). Data on the expression of the phlA-gfp and hcnA$g f p$ reporters on roots of different cereal cultivars represent the means from three and two individual repetitions over time of the same experiment, respectively, with three replicates per treatment in each experiment. Two-way analysis of variance revealed no significant experiment-treatment interaction, and all data for each treatment collected from the individual experiments were therefore pooled. Means were separated with Tukey's test $(P \leq 0.05)$.

\section{ACKNOWLEDGMENTS}

We thank V. Deytard for assistance with some experiments; A. Reber, F. Reinhard, and P. de Werra for helpful discussions; S. E. Lindow, D. K. Newman, and C. Blumer for providing vectors; F. Mascher for providing seed of cereals used in this study; and the Swiss National Science Foundation (project 3100A0-105881 and NRP-59 project 405940-115596) and the State Secretariat for Education and Research (project C04.0201) for their support.

\section{LITERATURE CITED}

Badri, D. V., and Vivanco, J. M. 2009. Regulation and function of root exudates. Plant Cell Environ. 32:666-681.

Baehler, E. 2005. Use of fluorescent proteins to monitor the regulation of antifungal activity in root-associated Pseudomonas fluorescens CHA0. $\mathrm{Ph} . \mathrm{D}$. thesis, University of Lausanne, Switzerland.

Baehler, E., Bottiglieri, M., Péchy-Tarr, M., Maurhofer, M., and Keel, C. 2005. Use of green fluorescent protein-based reporters to monitor balanced production of antifungal compounds in the biocontrol agent Pseudomonas fluorescens CHA0. J. Appl. Microbiol. 99:24-38.

Baehler, E., de Werra, P., Wick, L.Y., Péchy-Tarr, M., Mathys, S., Maurhofer, M., and Keel, C. 2006. Two novel MvaT-like global regulators control exoproduct formation and biocontrol activity in root-associated Pseudomonas fluorescens CHA0. Mol. Plant-Microbe Interact. 19:313-329.

Bais, H. P., Weir, T. L., Perry, L. G., Gilroy, S., and Vivanco, J. M. 2006. The role of root exudates in rhizosphere interactions with plants and other organisms. Annu. Rev. Plant Biol. 57:233-266.

Bao, Y., Lies, D. P., Fu, H., and Roberts, G. P. 1991. An improved Tn7based system for the single-copy insertion of cloned genes into chromosomes of gram-negative bacteria. Gene 109:167-168.

Barret, M., Frey-Klett, P., Guillerm-Erckelboudt, A. Y., Boutin, M., Guernec, G., and Sarniguet, A. 2009. Effect of wheat roots infected with the pathogenic fungus Gaeumannomyces graminis var. tritici on gene expression of the biocontrol bacterium Pseudomonas fluorescens Pf29Arp. Mol. Plant-Microbe Interact. 22:1611-1623.

Berg, G., and Smalla, K. 2009. Plant species and soil type cooperatively shape the structure and function of microbial communities in the rhizosphere. FEMS (Fed. Eur. Microbiol. Soc.) Microbiol. Ecol. 68:1-13.

Bergsma-Vlami, M., Prins, M. E., and Raaijmakers, J. M. 2005. Influence of plant species on population dynamics, genotypic diversity and antibiotic production in the rhizosphere by indigenous Pseudomonas spp. FEMS (Fed. Eur. Microbiol. Soc.) Microbiol. Ecol. 52:59-69.

Bloemberg, G. V. 2007. Microscopic analysis of plant-bacterium interactions using autofluorescent proteins. Eur. J. Plant Pathol. 119:301-309.

Brandl, M. T., Quinones, B., and Lindow, S. E. 2001. Heterogeneous transcription of an indoleacetic acid biosynthetic gene in Erwinia herbicola on plant surfaces. Proc. Natl. Acad. Sci. U.S.A. 98:3454-3459.

Bringhurst, R. M., Cardon, Z. G., and Gage, D. J. 2001. Galactosides in the rhizosphere: Utilization by Sinorhizobium meliloti and development of a biosensor. Proc. Natl. Acad. Sci. U.S.A. 98:4540-4545.

Czechowska, K., Johnson, D. R., and van der Meer, J. R. 2008. Use of flow cytometric methods for single-cell analysis in environmental microbiology. Curr. Opin. Microbiol. 11:1-8.

de Werra, P. 2009. Regulation of antifungal activity in root-associated Pseudomonas fluorescens $\mathrm{CHA} 0$ by plant-derived factors and enzymes involved in glucose metabolism. Ph.D. thesis no. 18341, ETH Zurich,
Switzerland.

de Werra, P., Baehler, E., Huser, A., Keel, C., and Maurhofer, M. 2008. Detection of plant-modulated alterations in antifungal gene expression in Pseudomonas fluorescens CHA0 on roots by flow cytometry. Appl. Environ. Microbiol. 74:1339-1349.

de Werra, P., Péchy-Tarr, M., Keel, C., and Maurhofer, M. 2009. Role of gluconic acid production in the regulation of biocontrol traits of Pseudomonas fluorescens CHA0. Appl. Environ. Microbiol. 75:4162-4174.

Dubuis, C., Keel, C., and Haas, D. 2007. Dialogs of root-colonizing biocontrol pseudomonads. Eur. J. Plant Pathol. 119:311-328.

Duffy, B. K., and Défago, G. 1999. Environmental factors modulating antibiotic and siderophore biosynthesis by Pseudomonas fluorescens biocontrol strains. Appl. Environ. Microbiol. 65:2429-2438.

Dulla, G., and Lindow, S. E. 2008. Quorum size of Pseudomonas syringae is small and dictated by water availability on the leaf surface. Proc. Natl. Acad. Sci. U.S.A. 105:3082-3087.

Gamalero, E., Lingua, G., Capri, F. G., Fusconi, A., Berta, G., and Lemanceau, P. 2004. Colonization pattern of primary tomato roots by Pseudomonas fluorescens A6RI characterized by dilution plating, flow cytometry, fluorescence, confocal and scanning electron microscopy. FEMS (Fed. Eur. Microbiol. Soc.) Microbiol. Ecol. 48:79-87.

Gross, H., and Loper, J. E. 2009. Genomics of secondary metabolite production by Pseudomonas spp. Nat. Prod. Rep. 26:1408-1446.

Haas, D., and Défago, G. 2005. Biological control of soil-borne pathogens by fluorescent pseudomonads. Nat. Rev. Microbiol. 3:307-319.

Haas, D., and Keel, C. 2003. Regulation of antibiotic production in rootcolonizing Pseudomonas spp. and relevance for biological control of plant disease. Annu. Rev. Phytopathol. 41:117-153.

Hakkila, K., Maksimow, M., Rosengren, A., Karp, M., and Virta, M. 2003. Monitoring promoter activity in a single bacterial cell by using green and red fluorescent proteins. J. Microbiol. Methods 54:75-79.

Højberg, O., Schnider, U., Winteler, H. V., Sørensen J., and Haas, D. 1999. Oxygen-sensing reporter strain of Pseudomonas fluorescens for monitoring the distribution of low-oxygen habitats in soil. Appl. Environ. Microbiol. 65:4085-4093.

Jousset, A., Rochat, L., Péchy-Tarr, M., Keel, C., Scheu, S., and Bonkowski, M. 2009. Predators promote defence of rhizosphere bacterial populations by selective feeding on non-toxic cheaters. ISME J. 3:666-674.

Keel, C., Weller, D. M., Natsch, A., Défago, G., Cook, R. J., and Thomashow, L. S. 1996. Conservation of the 2,4-diacetylphloroglucinol biosynthesis locus among fluorescent Pseudomonas strains from diverse geographic locations. Appl. Environ. Microbiol. 62:552-563.

Larrainzar, E., O'Gara, F., and Morrissey, J. P. 2005. Applications of autofluorescent proteins for in situ studies in microbial ecology. Annu. Rev. Microbiol. 59:257-277.

Laville, J., Blumer, C., Von Schroetter, C., Gaia, V., Défago, G., Keel, C., and Haas, D. 1998. Characterization of the hcnABC gene cluster encoding hydrogen cyanide synthase and anaerobic regulation by ANR in the strictly aerobic biocontrol agent Pseudomonas fluorescens CHA0. J. Bacteriol. 180:3187-3196.

Lugtenberg, B., and Kamilova, F. 2009. Plant-growth-promoting rhizobacteria. Annu. Rev. Microbiol. 63:541-556.

Maurhofer, M., Keel, C., Haas, D., and Défago, G. 1994. Pyoluteorin production by Pseudomonas fluorescens strain CHA0 is involved in the suppression of Pythium damping-off of cress but not of cucumber. Eur. J. Plant Pathol. 100:221-232.

Maurhofer, M., Baehler, E., Notz, R., Martinez, V., and Keel, C. 2004. Cross talk between 2,4-diacetylphloroglucinol-producing biocontrol pseudomonads on wheat roots. Appl. Environ. Microbiol. 70:1990-1998.

Mazurier, S., Corberand, T., Lemanceau, P., and Raaijmakers, J. M. 2009. Phenazine antibiotics produced by fluorescent pseudomonads contribute to natural soil suppressiveness to Fusarium wilt. ISME J. 3:977-991.

Mazzola, M., Funnell, D. L., and Raaijmakers, J. M. 2004. Wheat cultivarspecific selection of 2,4-diacetylphloroglucinol-producing fluorescent Pseudomonas species from resident soil populations. Microb. Ecol. 48:338-348.

Miller, W. G., and Lindow, S. E. 1997. An improved GFP cloning cassette designed for prokaryotic transcriptional fusions. Gene 191:149-153.

Miller, W. G., Leveau, J. H., and Lindow, S. E. 2000. Improved $g f p$ and inaZ broad-host-range promoter-probe vectors. Mol. Plant-Microbe Interact. 13:1243-1250.

Münch, A., Stingl, L., Jung, K., and Heermann, R. 2008. Photorhabdus luminescens genes induced upon insect infection. BMC Genomics 9:229. doi:10.1186/1471-2164-9-229. Published online.

Nancharaiah, Y. V., Wattiau, P., Wuertz, S., Bathe, S., Mohan, S. V., Wilderer, P. A., and Hausner, M. 2003. Dual labeling of Pseudomonas putida with fluorescent proteins for in situ monitoring of conjugal transfer of the TOL plasmid. Appl. Environ. Microbiol. 69:4846-4852.

Notz, R., Maurhofer, M., Schnider-Keel, U., Haas, D., and Défago, G. 2001. Biotic factors affecting expression of the 2,4-diacetylphlorogluci- 
nol biosynthesis gene phlA in Pseudomonas fluorescens biocontrol strain CHA0 in the rhizosphere. Phytopathology 91:873-881.

Péchy-Tarr, M., Bottiglieri, M., Mathys, S., Lejbølle, K. B., SchniderKeel, U., Maurhofer, M., and Keel, C. 2005. RpoN $\left(\sigma^{54}\right)$ controls production of antifungal compounds and biocontrol activity in Pseudomonas fluorescens CHA0. Mol. Plant-Microbe Interact. 18:260-272.

Péchy-Tarr, M., Bruck, D. J., Maurhofer, M., Fischer, E., Vogne, C., Henkels, M. D., Donahue, K. M., Grunder, J., Loper, J. E., and Keel, C. 2008. Molecular analysis of a novel gene cluster encoding an insect toxin in plant-associated strains of Pseudomonas fluorescens. Environ. Microbiol. 10:2368-2386.

Raaijmakers, J. M., de Bruijn, I., and de Kock, M. J. D. 2006. Cyclic lipopeptide production by plant-associated Pseudomonas spp.: Diversity, activity, biosynthesis, and regulation. Mol. Plant-Microbe Interact. 19:699-710.

Raaijmakers, J. M., Paulitz, T. C., Steinberg, C., Alabouvette, C., and Moënne-Loccoz, Y. 2009. The rhizosphere: A playground and battlefield for soilborne pathogens and beneficial microorganisms. Plant Soil 321:341-361.

Rudrappa, T., Splaine, R. E., Biedrzycki, M. L., and Bais, H. P. 2008. Cyanogenic pseudomonads influence multitrophic interactions in the rhizosphere. PLoS ONE 3:e2073. doi:10.1371/journal.pone.0002073. Published online.

Sambrook, J., and Russell, D. W. 2001 Molecular Cloning: A Laboratory Manual, 3rd ed. Cold Spring Harbor Laboratory Press, Cold Spring Harbor, NY, U.S.A.

Schnider-Keel, U., Seematter, A., Maurhofer, M., Blumer, C., Duffy, B., Gigot-Bonnefoy, C., Reimmann, C., Notz, R., Défago, G., Haas, D., and Keel, C. 2000. Autoinduction of 2,4-diacetylphloroglucinol biosynthesis in the biocontrol agent Pseudomonas fluorescens $\mathrm{CHA} 0$ and repression by the bacterial metabolites salicylate and pyoluteorin. J. Bacteriol. 182:1215-1225.

Shaner, N. C., Campbell, R. E., Steinbach, P. A., Giepmans, B. N., Palmer, A. E., and Tsien, R. Y. 2004. Improved monomeric red, orange and yellow fluorescent proteins derived from Discosoma sp. red fluorescent protein. Nat. Biotechnol. 22:1567-1572.

Sörensen, M., Lippuner, C., Kaiser, T., Misslitz, A., Aebischer, T., and Bumann, D. 2003. Rapidly maturing red fluorescent protein variants with strongly enhanced brightness in bacteria. FEBS (Fed. Eur. Biochem. Soc.) Lett. 552:110-114.

Steidle, A., Sigl, K., Schuhegger, R., Ihring, A., Schmid, M., Gantner, S., Stoffels, M., Riedel, K., Givskov, M., Hartmann, A., Langebartels, C. and Eberl, L. 2001. Visualization of $\mathrm{N}$-acylhomoserine lactone-mediated cell-cell communication between bacteria colonizing the tomato rhizosphere. Appl. Environ. Microbiol. 67:5761-5770.

Tecon, R., Binggeli, O., and van der Meer, J. R. 2009. Double-tagged fluorescent bacterial bioreporter for the study of polycyclic aromatic hydrocarbon diffusion and bioavailability. Environ. Microbiol. 11:2271-2283.

Unge, A., Tombolini, R., Molbak, L., and Jansson, J. K. 1999. Simultaneous monitoring of cell number and metabolic activity of specific bacterial populations with a dual $g f p-\operatorname{lux} A B$ marker system. Appl. Environ. Microbiol. 65:813-821.

Vieira, J., and Messing, J. 1991. New pUC-derived cloning vectors with different selectable markers and DNA replication origins. Gene 100:189-194.

Weller, D. M., Landa, B. B., Mavrodi, O. V., Schroeder, K. L., De La Fuente, L., Blouin Bankhead, S., Allende Molar, R., Bonsall, R. F., Mavrodi, D. V., and Thomashow, L. S. 2007. Role of 2,4-diacetylphloroglucinol-producing fluorescent Pseudomonas spp. in the defense of plant roots. Plant Biol. 9:4-20.

Yang, S., Peng, Q., Zhang, Q., Yi, X., Choi, C. J., Reedy, R. M. Charkowski, A. O., and Yang, C. H. 2008. Dynamic regulation of GacA in type III secretion, pectinase gene expression, pellicle formation, and pathogenicity of Dickeya dadantii (Erwinia chrysanthemi 3937). Mol. Plant-Microbe Interact. 21:133-142.

\section{AUTHOR-RECOMMENDED INTERNET RESOURCE}

WinMDI version 2.8 software: facs.scripps.edu/software.html 